\title{
Therapeutic Effect of Amitriptyline in Patients Suffering from Irritable Bowel Syndrome
}

\author{
Radkin Honzák* \\ Faculty of Medicine, Czech Republic
}

*Corresponding author: Radkin Honzak, Institute of General Practice, $1^{\text {st }}$ Faculty of Medicine, Charles University in Prague, Czech Republic

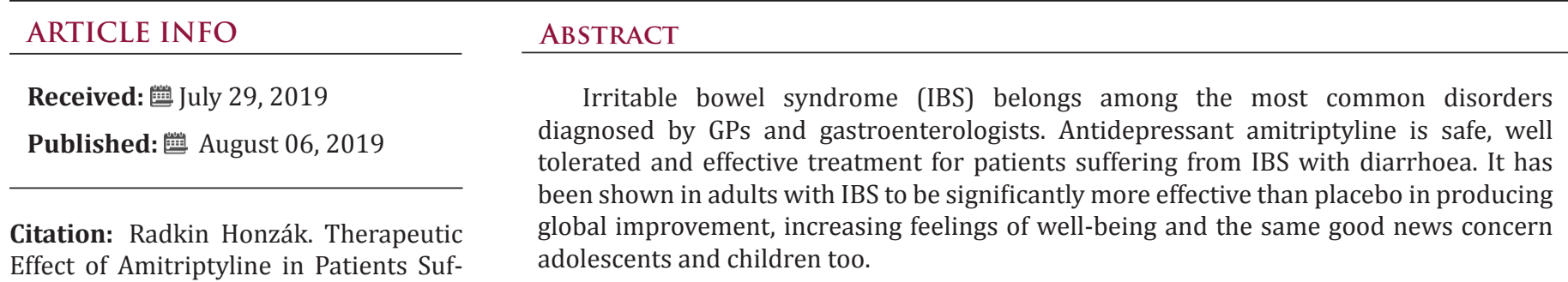

Effect of Amitriptyline in Patients Suffering from Irritable Bowel Syndrome. Biomed J Sci \& Tech Res 20(2)-2019. BJSTR. MS.ID.003437.
Keywords: Irritable Bowel Syndrome(IBS); Amitriptyline; Therapy

\section{Introduction}

Patients suffering from irritable bowel syndrome (IBS) form a part of the most frequent visitors in GP and gastroenterologist. Pathophysiology of irritable bowel syndrome consists of abnormal bowel motility including the pathological gastro-colic reflex with an abnormal character of stool consistency (IBS-C with constipation, IBS-D with diarrhoea and IBS-A - mixed type of both), visceral hypersensitivity and hyperalgesia with increased perception of physiological stimuli, bloating, postinfective consequences in the bottom-up type with gut dysmicrobia and abnormal intestinal secretion. Some patients exhibit different kind of food intolerance without allergy. There is also frequent ( 40\%) psychiatric comorbidity of major depressive disorder and anxiety spectrum disorders. The quality of life in IBS patients is lowered and patients show evidence of various social fears. As far as the emotions concerned there is a hypothesis that negative emotions even in subclinical intensity may play an important role in pathogenesis, clinical severity and illness experience too. It is especially anxiety, depression and hostility existing together under the umbrella of „neuroticism “, one of the features of Big Five.

These emotions may influence physical health. They are probably entangled with neurobiological and immunological factors and they are in relation with higher plasma concentrations of some proinflammatory cytokines (IL-1 $\beta$, IL-6, TNF, CRP) [1]. The prev alence of IBS is between $10-20 \%$ and the course is varied from spontaneous remission through intermittent episodes to lifelong severe chronic problem. There are a lot of therapeutic recommendations: adjustment of diet, probiotics, spasmolytics, opioids and opioid receptor agonists,sertrons, antibiotics, sulphonamides, anxiolytics, antidepressants, acupuncture, cognitive behavioral

psychotherapy and placebo because there are many placebo-reactors among IBS patients [2], and not only children. Amitriptyline is an antidepressant from the RUI family (Re-Uptake Inhibitors) known also as tricyclics. It blocks reuptake of two main neurotransmitters: norepinephrine (NE) and serotonin (5-HT), acts as an inhibitor of norepinephrine and dopamine transporters, and operates also as antagonist of $\mathrm{H} 1, \mathrm{M}$ and $\alpha 1$ receptors. Its analgesic potency (antagonist of substance P) is ensured by opioid receptors.

The first extra-psychiatric indication of tricyclics was pain treatment. Antidepressant became part of the WHO analgesic ladder in oncology: nonsteroidal analgesic + mild opioid + antidepressant. Tricyclics are much more effective than SSRI (selective serotonin reuptake inhibitors). Psychiatrists are the first specialists who started to treat IBS-D patients with amitriptyline after their recognition of unwanted side effects of this antidepressant - constipation [3]. Alike as in pain treatment the low dose of amitriptyline $(10-50 \mathrm{mg})$ is sufficient in IBS patient therapy. In comorbid psy- 
chiatric disorder the dose must be higher. Whereas as pure antidepressant is amitriptyline almost obsolete, in psychosomatic sphere as medication for IBS patients is obviously effective. Even in animal studies is amitriptyline used as therapeutical standard in the control group [4]. Its effect on visceral hypersensitivity is proven $[5,6]$, and low doses are sufficient because concentrations of tricyclics in tissues are ordinarily higher than their plasmatic concentrations [7]. Our psychosomatic group published in 1978 results of clinical trial with 30 patients [8].

We achieved improvement in 27 participants (full remission 12 , very good 10 , good 5 ). We assessed also the motility of GIT by X-ray with contrast and we found mainly a slowdown, only in one case we found mild acceleration of bowel movements; but this patient achieved full remission. To gastroenterology amitriptyline came into use with delay but with the same success [9], Vahedi et al. [10]. in 2008 have assessed the therapeutic role of antidepressant drugs, because they believed that there was insufficient evidence to support their use and prepared a double-blind trial with 54 patients. Participants were randomly selected, and half took 10 mg amitriptyline per day and half took placebo. After 2 months, the amitriptyline group showed greater $(\mathrm{P}<0.05)$ reduction in the incidence of loose stool and feeling of incomplete defecation. Patients receiving amitriptyline showed greater complete response, defined as loss of all symptoms, compared with those receiving placebo (68\% vs. $28 \%, \mathrm{P}=0.01$ ). Adverse effects were similar between the two groups. Chassany and Duracinsky [11] displayed some methodological doubts in connections with small number of participants in this trial, but authors in replay defended their results.

And Trinkley and Nahata in their metaanalysis [12] put this trial to methodological category 1A. Some reviews bring attention to therapeutic value of amitriptyline in this indication $[13,14]$, and there are also many studies dealing with the application in children and adolescents. Bahar et al. conducted a trial [15] with thirtythree adolescents (12-18 years) with newly diagnosed IBS. They were for 13 weeks on placebo arm $(n=17)$ or amitriptyline $(n=16)$. Their conclusions: Patients receiving amitriptyline were more likely to experience improvement from baseline in overall QOL at 6,10 , and 13 weeks ( $P=.019, .004$, and .013). They also experience improvement of diarrhoea. Mohammad et al. [16]. performed a subanalysis of the database of a multicenter randomized placebocontrolled trial designed to assess the efficacy of amitriptyline in children with abdominal pain-associated FGID (Functional Gastro-Intestinal Disorders; Rome II criteria). This included 50.7\% children with IBS, $42.4 \%$ with functional abdominal pain, and $6.9 \%$ diagnosed as having functional dyspepsia. Treatment satisfaction (good or excellent) 60.2\% Symptom relief (better) 48.2\%.

The longitudinal study [17] confirmed safety of amitriptyline in children also in long time duration (up to 30 months). Interesting are results of Saps'team [18]. They found the same good or excellent results ( $\sim 60 \%$ improvement) after placebo (40 children) as after amitriptyline (43 children). Trinkley and Nahata (cit.12) in their extensive review from literature found amitriptyline as effective but put it to the second group. The first and the most recommended is the group which include lubiprostone, linaclotide, rifaximin, fiber supplementation, and peppermint oil. There are two meta analyses dealing with the efficacy of TCAs in the management of IBS. In the first Rahimi et al. [19] in 2009 collected seven double blind placebo-controlled trials investigating the efficacy of TCAs in the management of IBS. published from 1966 until September 2008. The pooled relative risk for clinical improvement with TCA therapy was $1.93(95 \%$ CI: 1.44 to $2.6, \mathrm{P}<0.0001)$. and their conclusion of metaanalysis is that low dose TCAs exhibit clinically and statistically significant control of IBS symptoms.

The second is focused to amitriptyline only; Chao and Zang [20] found four randomized, placebo-controlled clinical trials that met their criteria and were included in the meta-analysis. The pooled relative risk for clinical improvement with amitriptyline therapy was 4.18 (95\% CI: 2.00 to $8.77, \mathrm{p}=0.0001$ ). Conclusion: It was thus concluded that amitriptyline exhibits a clinically and statistically significant control of IBS symptoms. The last published case report [21] presented a man suffering from IBS in stressful situations. Brief psychotherapy and $50 \mathrm{mg}$ of amitriptyline daily led to normalization of GIT functions within three months.

\section{References}

1. Muscatello MR, Bruno A, Scimeca G, Pandolfo G, Zoccali RA (2014) Role of negative effects in pathophysiology and clinical expression of irritable bowel syndrome. World J Gastroenterol 20(24): 7570-7586

2. Benninga MA, Mayer EA (2009) The Power of Placebo in Pediatric Functional Gastrointestinal Disease.

3. Gastroenterology 137(4): 1207-1210.

4. Boleloucký Z, Stranska R (1967) Amitriptylin in psychosomatic disorders of gastrointestinal tract. Activitas nervosa superior 9(4): 362-363.

5. Chun E, Soojung Yoon, Amna Parveen, Mirim Jin (2018) Alleviation of Irritable Bowel Syndrome-Like Symptoms and Control of Gut and Brain Response with Oral Administration of Dolichos lablab L. in a Mouse Model. Nutrients 10(10): 1475.

6. Thoua NM, Murray CD, Winchester WJ, Roy AJ, Pitcher MC, et al. (2008) modifies the visceral hypersensitivity response to acute stress in the irritable bowel syndrome. Aliment Pharmacol Ther 29:552-560.

7. Morgan V, Pickens D, Gautam S, Kessler R, Mertz H, et al. (2005) reduces rectal pain related activation of the anterior cingulate cortex in patients with irritable bowel syndrome. Gut 54(5): 601-607.

8. Gram LM (1974) Metabolism of tricyclic antidepressants. Dan Med Bull 21(6): 201-229.

9. Honzák R (1978) Therapeutic Use of in Irritable Colon. Čs Gastroent Výž 32(6): 379-385

10. Rajagopalan M, Kurian G, John J (1998) Symptom relief within the irritable bowel syndrome. J Gastroenterol Hepatol 13(7): 738-741.

11. Vahedi H, Merat S, Momtahen S, Kazzazi AS, Ghaffari N, et al. (2008) Clinical trial: the effect of amitriptyline in patients with diarrhoeapredominant irritable bowel syndrome. Aliment Pharmacol Ther 27(8): 678-684.

12. Chassany O, Duracinsky M (2008) Is amitriptyline really effective in diarrhoea-predominant irritable bowel syndrome? Aliment Pharmacol Ther 28:371-375 
13. Trinkley KE, Nahata NC (2014) Medication Management of Irritable Bowel Syndrome. Digestion 89(4): 253-267.

14. Sato M, Murakami M (2006) Treatment for irritable bowel syndromepsychotropic drugs, antidepressants and so on]. [Review] Nippon Rinsho 64(8): 1495-1500.

15. Lundberg GD (2008) Evidence that amitriptyline may be effective in treating diarrhea-predominant irritable bowel syndrome. Medscape Med 10(6):132.

16. Bahar RJ, Collins BS, Steinmetz B, Ament ME (2008) Double-blind, placebo-controlled trial of amitriptyline for the treatment of irritable bowel syndrome in adolescents. J Pediatr 152(5): 685-689.

17. Mohammad S (2014) Assessment of Abdominal Pain Through Global Outcomes and Recent FDA Recommendations in Children: Are We Ready for Change? JPGN 58(1): 46-50.

\section{ISSN: 2574-1241}

DOI: 10.26717/BJSTR.2019.20.003437

Radkin Honzák. Biomed J Sci \& Tech Res

This work is licensed under Creative Commons Attribution 4.0 License

Submission Link: https://biomedres.us/submit-manuscript.php
18. Teitelbaum JE, Arora R (2011) Long-term efficacy of low-dose tricyclic antidepressants for children with functional gastrointestinal disorders. J Pediatr Gastroenterol Nutr 53(3):260-264.

19. Saps M, Youssef N, Miranda A, Nurko S, Hyman P, et al. (2009) Multicenter randomized, placebo-controlled trial of in children with functional gastrointestinal disorders. Gastroenterology 137:1261-1269.

20. Rahimi R (2009) Efficacy of tricyclic antidepressants in irritable bowel syndrome: A meta-analysis. World J Gastroenterol 15(13): 1548-1553.

21. Chao GQ Zhang S (2013) A meta-analysis of the therapeutic effects of amitriptyline for treating irritable bowel syndrome. Intern Med 52(4): 419-424.

22. Honzák R (2019) Irritable bowel syndrome and emotions. Psychosom (in print).

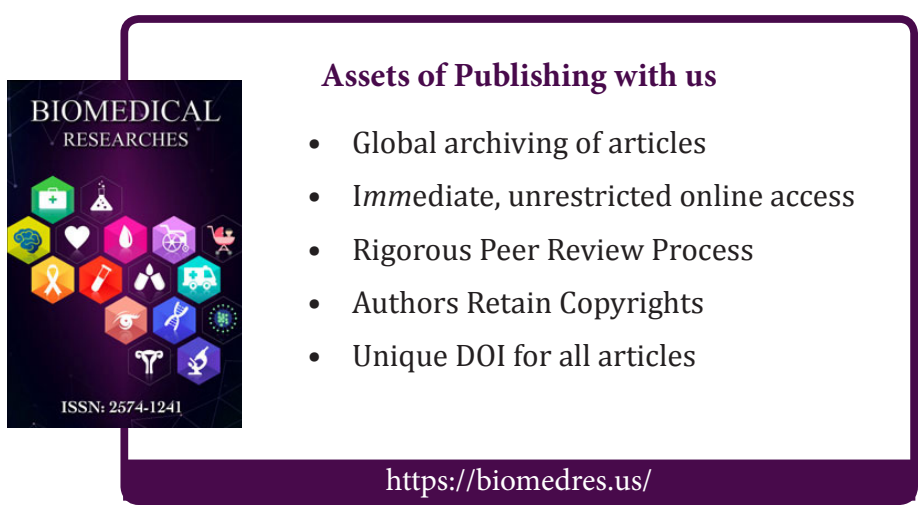

